\title{
The Impact of Technological Innovation on High-quality Economic Development Based on Chinese Provincial Data
}

\author{
Zejiong Zhou, Hongmei Chen* \\ Anhui University of Finance and economics, School of economics, Bengbu, Anhui, China \\ ${ }^{*}$ Corresponding author: 1756551947@qq.com
}

\begin{abstract}
Guided by the "New Five Development Concepts", this paper constructs an indicator system for high-quality economic development from the perspective of the effectiveness, coordination, innovation, sharing and sustainability of economic development, and analyzes the economic development of China's provinces from a provincial perspective. The entropy method is used to measure the comprehensive level of high-quality economic development in 30 provinces across the country from 2013 to 2019, and from the perspective of technological innovation, the technology market turnover is used to measure the basis of technological innovation, and a fixed effect model is established to reveal its relationship with economic high quality. The results show that: on the one hand, the overall level of high-quality development of China's economy is growing steadily, but there are obvious gaps between regions, and attention should be paid to shortening the gap between the rich and the poor to achieve more coordinated and comprehensive high-quality development; on the other hand, technological innovation can significantly promote the high-quality development of China's economy. We must continue to strengthen the core leading role of technological innovation, and promote technological innovation to serve the real economy. The government should formulate reasonable policies, implement environmental regulations to encourage enterprises to carry out technological innovation, and give full play to the driving effect of technological innovation on the high quality of the economy.
\end{abstract}

Keywords: High-quality economic development, Indicator system, Entropy method, Technological innovation, Fixed effect model.

\section{Introduction}

The 19th National Congress of the Communist Party of China proposed for the first time that China's economy should shift from a stage of high-speed growth to a stage of highquality development; the Sixth Plenary Session of the 19th CPC Central Committee proposed that, based on the new development stage, promote high-quality development, comprehensively deepen reform and opening up, promote common prosperity, and promote scientific and technological self-reliance, adhere to the guarantee and improvement of people's livelihood in the process of development, adhere to the harmonious coexistence of man and nature, coordinate development and security, and jointly promote the prosperity of the people, the prosperity of the country, and the beauty of China. Guo Ruiping et al. (2020) pointed out that Xi Jinping's thought of common prosperity is a response to China's unbalanced and insufficient development, with shared development as the concept, targeted poverty alleviation and rural revitalization as strategies to promote common prosperity [1]. Promoting the common prosperity of all people in the process of promoting high-quality development is the guiding ideology and important goal of economic and social development proposed in the "14th Five-Year Plan" and the 2035 Vision. High-quality economic development will become an important guiding ideology for local economic development in the new era [2]. Fully implement the spirit of the 19th National Congress of the Communist Party of China and the Sixth Plenary Session of the 19th Central Committee, coordinate both domestic and international situations, coordinate epidemic prevention and control and economic and social development, coordinate development and security, and adhere to the general tone of seeking progress while maintaining stability [3]. The new development concept was fully implemented, the construction of a new development pattern was accelerated, the economy maintained a good momentum of development, the self-reliance and selfimprovement of science and technology was actively promoted, the reform and opening up was continuously deepened, the poverty alleviation was won as scheduled, and absolute poverty was eliminated. However, China has not completely achieved economic transformation, and has not yet formed a good sustainable economic development model, and high-quality economic development needs to be achieved. The development of agriculture, manufacturing and modern service industry is deficient, especially compared with developed countries, the development of service industry is relatively backward, and the industrial supporting system is not perfect. In the context of the new era, the scale of the new economy is still small, the ability to support development is insufficient, and its proportion is not large, and economic development lacks momentum. The ability to support the high-quality development of the national economy still needs to be improved to meet the requirements of high-quality economic development in the new era. In addition, the investment in scientific and technological innovation is insufficient, the benefits are low, and the innovation and research and development capabilities are extremely lacking. Although we insist on increasing investment in research and development, due to the late start and weak foundation, the cost of investment is high, the economic efficiency is low, the innovation and research and development capacity has always been maintained at a low level, scientific research innovation lacks vitality, and the transformation of economic development mode is hindered. The system for promoting 
economic development is not yet perfect, and the development environment is not yet mature [4]. In recent years, with the continuous development of emerging technologies and the continuous construction of electronic and informatization, technological means have become more and more important to promote financial technology. At this stage, there are many uncertainties in China's economic development, and there are still obstacles to achieving highquality economic development. In addition, the gap between the rich and the poor still exists in China. Although it is out of absolute poverty, it is still in a state of relative poverty. There are still gaps in regional development. Moreover, due to the constraints of factors, ecological environment, etc. between regions, technological innovation has little impact on highquality economic development. Obviously, the high-quality economic benefits of financial technology services are not significant, which hinders China's economic leap to a higher level. Therefore, studying the high-quality economic development among provinces across the country, clarifying the differences in economic development between provinces, and studying its impact on high-quality economic development from the perspective of technological innovation will help promote high-quality economic development and contribute to the realization of high-quality economic development. Common prosperity has important practical significance.

The idea of common prosperity is the core content of Deng Xiaoping Theory. Liang Chao et al. (2017) proposed that the idea of common prosperity is based on the abundance of material materials, and must be based on the actual level of productivity to strictly prevent polarization [5]. Gao Haibo (2021) mentioned that paradoxical poverty refers to the phenomenon that the more laborers work, the poorer they become [6]. Based on this, he compared the poverty problems of Western capitalism and Chinese socialism, and believed that common prosperity is a great practice to solve this dilemma, providing Chinese wisdom for poverty eradication.

Due to different research perspectives, the connotation of high-quality economic development in domestic academic circles is slightly different, and the related research is generally rich. Liu Libo et al. (2018) believe that high-quality economic development is the coordinated development of five in one, and at the same time achieves high efficiency, fairness and sustainability [7]. Zhao Jianbo et al. (2019) believe that to achieve high-quality economic development, it is necessary to systematically grasp its connotation and development mechanism, implement precise policy support, and allow the whole people to share the fruits of economic development [8]. Cao Xiaochen (2021) measured and analyzed the five major economic development ideas, and used the entropy weight method for empirical analysis to conclude that innovative development, green development, and coordinated development have a significant impact on high-quality economic development. We must focus on multiple aspects to coordinate and lead high-quality economic development [9]. Li Ruiji (2021) believes that the connotation of high-quality economic development is to focus not only on economic development, but also on social benefits, promote economic transformation, and promote high-quality demand [10].

There are abundant researches on the impact mechanism of technological innovation on high-quality economic development. Miao Liran (2020) conducted an empirical analysis by using the entropy weight method, and the results show that technological innovation has a positive effect on economic development, but the effect varies from place to place [11]. Lu Mingxiang et al. (2020) empirically analyzed that the R\&D investment in industrial and high-tech industries and the upgrading of consumption structure can improve the efficiency of resource utilization. It is necessary to formulate effective and reasonable strategies according to the actual situation of the region to promote the economic development of the western backward regions [12]. Ran Zheng et al. (2021) analysis that innovation capability is an important promotion mechanism for high-quality economic development, but there is an economic cycle effect. And the innovation ability can only promote the high-quality development of the regional economy when the scale of the city reaches a certain level [13].

Through the literature review, it is found that in the related literature on technological innovation and economic high quality in the academic circle, the research on the two aspects has been relatively abundant, but the following two facts have been ignored: First, high-quality development needs to be supported by technological innovation. , and technological innovation requires a sound innovation-oriented market mechanism. Second, the main body of technological innovation is the enterprise, and the technological innovation capability of the enterprise largely determines the technological innovation level of the market economy. This paper measures the level of technological innovation by the technology market turnover, and builds a comprehensive level indicator system for high-quality economic development based on new development concepts. From a macro perspective, it deeply analyzes the impact of technological innovation on high-quality economy, and provides decision-making basis and theoretical support for high-quality development to promote high-quality economic development.

\section{Measurement of High-quality Development}

\subsection{Construction of High-quality Development Index System}

According to the party's "19th National Congress" and the 6th Plenary Session of the 19th Central Committee on highquality development, high-quality development pays more attention to the quality of economic development rather than blindly pursuing the speed of development, and takes into account both economic development and social benefits [14]. Based on the new five development concepts, this paper constructs an evaluation system for high-quality economic development from the perspectives of effectiveness, coordination, innovation, sharing, and sustainability. Based on the five development concepts of high-quality economic development, the indicator system of high-quality economic development level constructed in this paper includes 5 firstlevel indicators and 15 second-level indicators, as shown in Table 1. 
Table 1. Specific indicator system for high-quality economic development

\begin{tabular}{|c|c|c|c|c|}
\hline $\begin{array}{l}\text { First-level } \\
\text { indicators }\end{array}$ & Second-level indicators & Indicator measurement method & Unit & $\begin{array}{l}\text { Nature of } \\
\text { indicators }\end{array}$ \\
\hline \multirow{4}{*}{ Effectiveness } & Scale of economic growth & GDP per capita & Yuan/person & Positive \\
\hline & $\begin{array}{l}\text { Service industry growth } \\
\text { scale }\end{array}$ & $\begin{array}{c}\text { Tertiary industry output value } \\
\text { added }\end{array}$ & 100 million yuan & Positive \\
\hline & $\begin{array}{c}\text { Industrial Structure } \\
\text { Upgrade }\end{array}$ & $\begin{array}{c}\text { Tertiary Industry Output Value } \\
\text { Added/GDP }\end{array}$ & $\%$ & Positive \\
\hline & $\begin{array}{l}\text { Dependence on foreign } \\
\text { trade }\end{array}$ & Total import and export/GDP & $\%$ & Positive \\
\hline \multirow{3}{*}{ Coordination } & $\begin{array}{l}\text { Coordination level of } \\
\text { consumption of urban and } \\
\text { rural residents }\end{array}$ & $\begin{array}{l}\text { Per capita consumption } \\
\text { expenditure of urban residents/per } \\
\text { capita consumption expenditure of } \\
\text { rural residents }\end{array}$ & - & Positive \\
\hline & Urbanization rate & Urban population/total population & $\%$ & Positive \\
\hline & $\begin{array}{l}\text { Income coordination level } \\
\text { of urban and rural } \\
\text { residents }\end{array}$ & $\begin{array}{c}\text { Per capita disposable income of } \\
\text { urban residents/per capita } \\
\text { disposable income of rural } \\
\text { residents }\end{array}$ & - & Positive \\
\hline \multirow{3}{*}{ Innovation } & $\begin{array}{c}\text { Fiscal Science and } \\
\text { Technology Expenditure }\end{array}$ & & RMB 10,000 & Positive \\
\hline & $\begin{array}{l}\mathrm{R} \& \mathrm{D} \text { expenditure } \\
\text { intensity }\end{array}$ & $\begin{array}{l}\text { R\&D expenditureof industrial } \\
\text { enterprises above designated } \\
\text { size/GDP }\end{array}$ & $\%$ & Positive \\
\hline & $\begin{array}{c}\text { Number of granted patent } \\
\text { applications }\end{array}$ & & Number & Positive \\
\hline \multirow{3}{*}{ Sharing } & $\begin{array}{l}\text { Growth of per capita } \\
\text { disposable income }\end{array}$ & & RMB 10,000 & Positive \\
\hline & $\begin{array}{l}\text { Urban registered } \\
\text { unemployed persons }\end{array}$ & & People 10,000 & Negative \\
\hline & $\begin{array}{l}\text { Fiscal general public } \\
\text { service expenditure }\end{array}$ & & RMB 10,000 & Positive \\
\hline & Green Coverage & & $\%$ & Positive \\
\hline Sustainability & $\begin{array}{l}\text { Investment in } \\
\text { environmental pollution } \\
\text { control }\end{array}$ & $\begin{array}{l}\text { Completed investment in industrial } \\
\text { pollution control }\end{array}$ & RMB 10,000 & Positive \\
\hline
\end{tabular}

\subsection{Evaluation of the Comprehensive Level of High-quality Development}

\subsubsection{Research Methods}

Based on the index system constructed by the above data, this paper uses the entropy method to measure the highquality development level of each province in China. Specific steps are as follows:

(1) Since the dimension and order of magnitude of each index are different, in order to eliminate the influence of different dimensions on the measurement results, it is necessary to perform dimensionless processing on each index and homogenize the heterogeneous indexes [15]. The specific calculation formula is as follows:

$$
X_{i j}=\left|X_{i j}\right|, i=1,2, \ldots n ; j=1,2, \ldots m
$$

The positive indicator is: $X^{\prime}{ }_{i j}=\frac{X_{i j}-\min \left(X_{i j}\right)}{\max \left(X_{i j}\right)-\min \left(X_{i j}\right)}$.

The inverse indicator is: $X^{\prime}{ }_{i j}=\frac{\max \left(X_{i j}\right)-X_{i j}}{\max \left(X_{i j}\right)-\min \left(X_{i j}\right)}$

(2) After standardizing the data, calculate the entropy value and weight of each index. The calculation process is as follows:

The proportion of indicators is: $w_{i j}=\frac{x_{i j}^{\prime}}{\sum_{i=1}^{m} x_{i j}^{\prime}}$
The formula for calculating the entropy value is as follows:

$$
e_{j}=-\frac{1}{\ln m} \sum_{i=1}^{m}\left(w_{i j} \cdot \ln w_{i j}\right)
$$

(3) Calculate the difference system of each index. The specific formula is as follows:

$$
d_{j}=1-e_{j}
$$

(4) Calculate the weight value of each indicator. The specific formula is as follows:

$$
w_{j}=\frac{d_{j}}{\sum_{j=1}^{m} d_{j}}
$$

(5) Calculate the comprehensive economic index. The specific formula is as follows:

$$
\mathrm{I}=x_{i j}^{\prime} \cdot w_{j}
$$

Where, $e_{j}$ is the entropy value of the jth index, $w_{j}$ is the weight of the jth index, and $\mathrm{m}$ is the number of years. The entropy method is used to assign weights to each indicator of the panel data of various provinces in China, and finally the economic high-quality development index is calculated based 
on the comprehensive weights.

\subsubsection{Data Sources}

In order to ensure the integrity and availability of the data, the panel data of 30 provinces in China (excluding Tibet) from 2013 to 2019 were selected, and the missing data were replaced by the mean method.

\subsubsection{Analysis of High-quality Comprehensive Evaluation Results}

Based on the five development concepts, this paper measures the comprehensive index of high-quality development of China's 30 provinces (autonomous regions and municipalities) from 2013 to 2019 , and the final result retains four decimal places. The results are shown in Tables 2 and 3 .

(1) Time series characteristics of high-quality development. On the whole, from the average of the national high-quality development comprehensive index, it can be concluded that the comprehensive level of high-quality economic development in China has shown an upward trend, from 0.2016 in 2013 to 0.2405 in 2019 . The composite index was relatively stable, with a small increase, maintaining the basic pace of making progress while maintaining stability. From the perspective of provinces and regions, the comprehensive level of high-quality development in each province and region has gradually improved from 2013 to 2018. Among them, the high-quality development index of Guangdong Province has always ranked first and has the largest increase, from 0.4302 in 2013 to 0.6897 in 2019 , with a growth rate of $60.32 \%$; Jiangsu ranks second in the comprehensive level of highquality development, from 0.4271 in 2013 to 0.6897 In 2019, it reached 0.5353 , with a growth rate of $25.33 \%$; Beijing, Shanghai, and Zhejiang followed closely, and Jilin and Qinghai ranked at the bottom of the high-quality development ranking. This shows that the degree of opening to the outside world can promote high-quality economic development to a certain extent, and areas with a high degree of opening to the outside world can gather high-quality resources, making it easier to achieve high-quality economic development. From a regional perspective, the southern coastal areas have the highest level of high-quality development and a larger increase, from 0.3202 in 2013 to 0.4136 in 2019 , with a growth rate of $29.17 \%$; followed by the northern coastal areas, from 0.2339 in 2013 to 2019 It reached 0.3141 , with a growth rate of $34.29 \%$; the high-quality development level of the middle reaches of the Yangtze River increased the fastest, and the comprehensive index of high-quality development reached 0.2278 from 0.1514 in 2013 to 0.2278 in 2019, with a growth rate of $50.46 \%$. However, in 2019, the comprehensive level of high-quality development in most regions in the Northeast and the middle reaches of the Yellow River did not rise but fell; the comprehensive level of highquality development in the southwest region, except for Sichuan and Guizhou, declined.

Table 2. High-quality development index and rank of provinces in China

\begin{tabular}{|c|c|c|c|c|c|c|c|c|c|c|c|c|c|c|}
\hline Year & \multicolumn{2}{|c|}{2013} & \multicolumn{2}{|c|}{2014} & \multicolumn{2}{|c|}{2015} & \multicolumn{2}{|c|}{2016} & \multicolumn{2}{|c|}{2017} & \multicolumn{2}{|c|}{2018} & \multicolumn{2}{|c|}{2019} \\
\hline Region & Score & Rank & Score & Rank & Score & Rank & Score & Rank & Score & Rank & Score & Rank & Score & Rank \\
\hline Beijing & 0.3972 & 3 & 0.4043 & 3 & 0.3872 & 3 & 0.3907 & 4 & 0.4221 & 4 & 0.4539 & 3 & 0.4336 & 4 \\
\hline Tianjin & 0.2588 & 7 & 0.2662 & 7 & 0.2670 & 7 & 0.2581 & 7 & 0.2405 & 7 & 0.2545 & 8 & 0.2352 & 11 \\
\hline Hebei & 0.1589 & 16 & 0.1847 & 11 & 0.1675 & 15 & 0.1591 & 18 & 0.1772 & 17 & 0.1945 & 17 & 0.2054 & 15 \\
\hline Shanxi & 0.1593 & 15 & 0.1376 & 25 & 0.1368 & 25 & 0.1420 & 25 & 0.1649 & 19 & 0.1737 & 20 & 0.1728 & 19 \\
\hline $\begin{array}{c}\text { Inner } \\
\text { Mongolia }\end{array}$ & 0.1701 & 14 & 0.1801 & 13 & 0.1610 & 17 & 0.1621 & 17 & 0.1662 & 18 & 0.1629 & 22 & 0.1497 & 24 \\
\hline Liaoning & 0.2219 & 8 & 0.2179 & 9 & 0.1808 & 11 & 0.1862 & 12 & 0.1876 & 15 & 0.1996 & 16 & 0.1890 & 18 \\
\hline Jilin & 0.1235 & 27 & 0.1249 & 28 & 0.1198 & 28 & 0.1215 & 29 & 0.1217 & 28 & 0.1272 & 28 & 0.1252 & 28 \\
\hline Heilongjiang & 0.1218 & 28 & 0.1158 & 29 & 0.1113 & 30 & 0.1104 & 30 & 0.1056 & 30 & 0.1074 & 30 & 0.1035 & 30 \\
\hline Shanghai & 0.3692 & 4 & 0.3796 & 4 & 0.3858 & 4 & 0.4212 & 3 & 0.4396 & 3 & 0.4534 & 4 & 0.4296 & 5 \\
\hline Jiangsu & 0.4271 & 2 & 0.4101 & 2 & 0.4306 & 2 & 0.4670 & 2 & 0.4709 & 2 & 0.5228 & 2 & 0.5353 & 2 \\
\hline Zhejiang & 0.3330 & 5 & 0.3368 & 6 & 0.3489 & 5 & 0.3789 & 5 & 0.3815 & 5 & 0.4240 & 5 & 0.4390 & 3 \\
\hline Anhui & 0.1793 & 11 & 0.1687 & 16 & 0.1813 & 10 & 0.2277 & 9 & 0.2305 & 9 & 0.2514 & 9 & 0.2572 & 8 \\
\hline Fujian & 0.2203 & 9 & 0.2241 & 8 & 0.2326 & 8 & 0.2311 & 8 & 0.2376 & 8 & 0.2601 & 7 & 0.2591 & 7 \\
\hline Jiangxi & 0.1209 & 29 & 0.1270 & 27 & 0.1376 & 24 & 0.1458 & 24 & 0.1624 & 21 & 0.1809 & 18 & 0.1965 & 17 \\
\hline Shandong & 0.3051 & 6 & 0.3452 & 5 & 0.3250 & 6 & 0.3597 & 6 & 0.3649 & 6 & 0.3751 & 6 & 0.3823 & 6 \\
\hline Henan & 0.1746 & 13 & 0.1831 & 12 & 0.1737 & 14 & 0.2086 & 11 & 0.2225 & 10 & 0.2387 & 10 & 0.2417 & 9 \\
\hline Hubei & 0.1561 & 19 & 0.1738 & 15 & 0.1806 & 12 & 0.2099 & 10 & 0.2141 & 11 & 0.2324 & 11 & 0.2360 & 10 \\
\hline Hunan & 0.1493 & 21 & 0.1493 & 21 & 0.1657 & 16 & 0.1695 & 16 & 0.1859 & 16 & 0.2065 & 13 & 0.2212 & 12 \\
\hline Guangdong & 0.4302 & 1 & 0.4212 & 1 & 0.4736 & 1 & 0.5278 & 1 & 0.5927 & 1 & 0.6658 & 1 & 0.6897 & 1 \\
\hline Guangxi & 0.1504 & 20 & 0.1500 & 20 & 0.1581 & 18 & 0.1537 & 20 & 0.1565 & 24 & 0.1570 & 24 & 0.1537 & 23 \\
\hline Hainan & 0.1412 & 25 & 0.1392 & 24 & 0.1274 & 26 & 0.1233 & 27 & 0.1245 & 27 & 0.1317 & 27 & 0.1287 & 27 \\
\hline Chongqing & 0.1829 & 10 & 0.1891 & 10 & 0.1887 & 9 & 0.1821 & 13 & 0.1935 & 12 & 0.2039 & 14 & 0.2025 & 16 \\
\hline Sichuan & 0.1562 & 18 & 0.1580 & 18 & 0.1575 & 20 & 0.1723 & 15 & 0.1934 & 13 & 0.2121 & 12 & 0.2181 & 13 \\
\hline Guizhou & 0.1482 & 22 & 0.1483 & 22 & 0.1464 & 22 & 0.1468 & 23 & 0.1567 & 23 & 0.1650 & 21 & 0.1655 & 21 \\
\hline Yunnan & 0.1571 & 17 & 0.1607 & 17 & 0.1580 & 19 & 0.1579 & 19 & 0.1646 & 20 & 0.1749 & 19 & 0.1724 & 20 \\
\hline Shaanxi & 0.1779 & 12 & 0.1748 & 14 & 0.1795 & 13 & 0.1765 & 14 & 0.1902 & 14 & 0.2013 & 15 & 0.2069 & 14 \\
\hline Gansu & 0.1440 & 23 & 0.1458 & 23 & 0.1390 & 23 & 0.1490 & 22 & 0.1477 & 25 & 0.1498 & 25 & 0.1489 & 25 \\
\hline Qinghai & 0.1094 & 30 & 0.1133 & 30 & 0.1167 & 29 & 0.1231 & 28 & 0.1150 & 29 & 0.1192 & 29 & 0.1158 & 29 \\
\hline Ningxia & 0.1244 & 26 & 0.1364 & 26 & 0.1249 & 27 & 0.1382 & 26 & 0.1317 & 26 & 0.1361 & 26 & 0.1339 & 26 \\
\hline Xinjiang & 0.1419 & 24 & 0.1551 & 19 & 0.1490 & 21 & 0.1524 & 21 & 0.1575 & 22 & 0.1614 & 23 & 0.1573 & 22 \\
\hline
\end{tabular}


(2) Characteristics of high-quality development regions. There are significant regional differences in high-quality development. The difference between the maximum and minimum comprehensive scores from 2013 to 2019 is 0.3208 , $0.3079,0.3623,0.4174,0.4871,0.5585$, and 0.5862 . The gap between provinces and cities generally shows an upward trend, indicating that China's high-quality economic development is still unbalanced, the economic gap is large, and there is still a certain distance to achieve common prosperity. The comprehensive level of high-quality development in coastal areas is significantly higher than that in other areas, among which the southern coastal area is the highest, but the development gap between regions is large, and the development gap becomes more and more obvious as time goes on. The comprehensive score of high-quality development in coastal areas ranged from 0.1412 to 0.4302 in $2013,0.1287$ to 0.6897 in 2019 . From the distribution of the eight major economic regions, the comprehensive level of high-quality development is: coastal areas $>$ riverside areas $>$ inland frontier areas. This may be due to the relatively high degree of opening to the outside world in the coastal and riverside areas, the early start of economic development, and the more reasonable economic development system.

Table 3. Average value of high-quality development index

\begin{tabular}{l|l|l|l|l|l|l|l}
\hline Year & 2013 & 2014 & 2015 & 2016 & 2017 & 2018 & 2019 \\
\hline National average & 0.2016 & 0.2051 & 0.2045 & 0.2157 & 0.2243 & 0.2400 & 0.2405 \\
\hline Northeast region average & 0.1557 & 0.1529 & 0.1373 & 0.1393 & 0.1383 & 0.1447 & 0.1392 \\
\hline Northern coastal average & 0.2339 & 0.3001 & 0.2867 & 0.2919 & 0.3012 & 0.3195 & 0.3141 \\
\hline $\begin{array}{l}\text { Southern coastal average } \\
\begin{array}{c}\text { Average value of the middle reaches } \\
\text { of the Yellow River }\end{array}\end{array}$ & 0.3202 & 0.3185 & 0.3332 & 0.3582 & 0.3745 & 0.4096 & 0.4136 \\
$\begin{array}{c}\text { Average value of the middle reaches } \\
\text { of the Yangtze River }\end{array}$ & 0.1514 & 0.1689 & 0.1628 & 0.1723 & 0.1859 & 0.1941 & 0.1928 \\
\hline Southwest average & 0.1590 & 0.1612 & 0.1663 & 0.1882 & 0.1982 & 0.2178 & 0.2278 \\
\hline Northwest Region Average & 0.1300 & 0.1377 & 0.1324 & 0.1406 & 0.1380 & 0.1416 & 0.1390 \\
\hline
\end{tabular}

\section{Empirical Analysis}

\subsection{Model Construction}

In order to study whether technological innovation can promote high-quality economic development, this paper mainly adopts the panel regression analysis method to study the impact of technological innovation on the level of highquality development. The panel regression equation is established as follows:

$$
\ln Y_{i t}=\alpha_{0}+\alpha_{1} \ln X_{i t}+\alpha_{2} \ln A_{1_{i t}}+\alpha_{3} \ln A_{2_{i t}}+\alpha_{4} \ln A_{3 i t}+\varepsilon_{i t}
$$

Among them, $\mathrm{i} \in[1,30], \mathrm{t} \in[1,7] ; \mathrm{Y}$ is the comprehensive level of high-quality development of the i province and city in period $\mathrm{t}, \mathrm{X}$ is the core explanatory variable technology market turnover; $\mathrm{A}$ is a series of control variables, in which $A_{1}, A_{2}, A_{3}$ are environmental regulation, government intervention and industrialization degree respectively; $\varepsilon_{i t}$ is a random disturbance item.

\subsection{Variable Measurement and Description}

\subsubsection{Measurement of High-quality Development Level}

The comprehensive level score (Y) of high-quality development. The comprehensive score of high-quality development level calculated by the entropy method above is used as the measurement index of high-quality development level.

\subsubsection{Measurement of Technological Innovation Level}

Technical market turnover (X). It can reflect the development of the technology market and reflect the level of technological innovation.

\subsubsection{Control Variables}

Referring to the existing literature, the following indicators were selected as control variables:
(1) Environmental regulation $\left(A_{1}\right)$ : Environmental regulation can affect the growth of the green economy, thereby promoting the high quality of the economy and achieving sustainable economic development. It is measured by the proportion of electricity consumption to GDP [16].

(2) Government Intervention $\left(A_{2}\right)$ : The proportion of the local government's general budget expenditure in the GDP is used as a proxy variable for the degree of government intervention. Fiscal expenditure is an important means of government macro-control. Appropriate use of control tools can make up for market failures, improve the efficiency of factor flow and resource allocation, and enhance economic externalities [17].

(3) Degree of industrialization $\left(A_{3}\right)$. The upgrading of the industrial structure will help to promote the high quality of the economy and transform the driving force of the economy, which is measured by the proportion of the added value of the secondary industry to GDP [18].

\subsection{The Data Comes from Descriptive Statistics}

In order to ensure the integrity and availability of the data, this paper selects the panel data of 30 provinces (autonomous regions and municipalities) in the country from 2013 to 2019 as the research sample, the missing data is filled by the mean method, and the data is processed by logarithm. The data mainly comes from the statistics database of China Economic Net.

The descriptive statistics of the study sample are shown in Table 4. It can be seen from Table 4 that the maximum value of the comprehensive index of high-quality economic development is 0.689684, and the minimum value is 0.103475 . There are also obvious gaps in the development level of technological innovation among regions, the maximum value is 57000000 , and the minimum value is only 
Table 4. Descriptive Statistics Results

\begin{tabular}{cccccc}
\hline Variable & Obs & Mean & Std. Dev. & Min & Max \\
\hline Y & 210 & 0.221516 & 0.114785 & 0.103475 & 0.689684 \\
X & 210 & 4157029 & 7927659 & 6524.6200 & 57000000 \\
A1 & 210 & 0.103690 & 0.071704 & 0.032907 & 0.394730 \\
A2 & 210 & 0.2671230 & 0.113436 & 0.11997 & 0.753436 \\
A3 & 210 & 40.769950 & 7.904460 & 16.20000 & 55.760000 \\
lnY & 210 & -1.611100 & 0.432101 & -2.26843 & -0.371520 \\
lnX & 210 & 14.015890 & 1.761549 & 8.783338 & 17.857730 \\
lnA1 & 210 & -2.428620 & 0.527062 & -3.414060 & -0.929550 \\
lnA2 & 210 & -1.396070 & 0.382245 & -2.120510 & -0.283110 \\
lnA3 & 210 & 3.684164 & 0.234123 & 2.785011 & 4.021057 \\
est_fe & 210 & 1 & 0 & 1 & 1 \\
est_re & 210 & 1 & 0 & 1 & 1 \\
\hline
\end{tabular}

\subsection{Empirical Result}

According to the result of the Hausman test, it can be concluded that the $p$ value is less than 0.05 , and the null hypothesis is rejected, that is, the error term is related to the explanatory variable [19]. Therefore, a fixed-effects regression model should be established in this study sample. The regression results of the fixed effects model are shown in Table 5.

It can be seen from Table 5 that the coefficient of technological innovation on economic high quality is 0.115595 , and the accompanying probability $\mathrm{p}=0.000<0.05$, which has passed the significance test at the 5\% level, which indicates that technological innovation can positively promote economic high quality developing. Technological innovation is an important driving force for China's transformation, and innovation-driven support and leadership is the key to transforming innovative resources and technologies into high-quality development advantages. Building a strong country in science and technology and developing a modern industrial system are important guidelines for the high-quality development of China's economy. China's actual economic situation requires technological innovation to build new advantages for development, grasp the trends and opportunities of historical changes, seek opportunities in development, adhere to selfreliance and innovation to tackle key problems, take technological innovation as the core, lead the development of financial technology, and accelerate the formation of economic high Quality development pattern.

From the results of the regression of the control variables, the accompanying probability $\mathrm{p}=0.000<0.05$, all passed the significance test at the 5\% level. Among them, the coefficient of environmental regulation is 0.364675 , indicating that environmental regulation can positively promote high-quality economic development, and reasonable environmental policies can internalize the external and external costs of environmental pollution of enterprises, and improve the enthusiasm of enterprises for innovation management. Moreover, the production of green technology can promote the transformation and upgrading of the industrial structure, thereby stimulating the technological innovation potential of enterprises. The coefficients of government intervention and the degree of industrialization are -0.97576 and -0.64702 , respectively, and the coefficient values are all negative numbers, showing an inhibitory effect on high-quality economic development. Improper government intervention will curb economic development, cause the economy to decline instead of increasing, disrupt the market order, and make the economy unbalanced. However, the degree of industrialization inhibits the high-quality development of the economy, indicating that the process of industrialization has not been synchronized with modernization, and the development of industrialization still has the problem of unbalanced and insufficient development. On the one hand, the problem of low-level overcapacity is prominent; on the other hand, the development of high-end manufacturing is not sufficient, and the core technology relies heavily on imports and foreign-funded enterprises. The unbalanced development of the real economy and the virtual economy has caused the overall quality of economic development to be low, unable to meet the current needs of high-quality economic transformation.

Table 5. Panel model regression analysis results

\begin{tabular}{ccccc}
\hline Variable & Coefficient & Standard Error & t-value & P-value \\
\hline $\ln \mathrm{X}$ & 0.115595 & 0.011124 & 10.39 & 0.000 \\
$\ln \mathrm{A} 1$ & 0.364675 & 0.046166 & 7.90 & 0.000 \\
$\ln \mathrm{A} 2$ & -0.97576 & 0.060754 & -16.06 & 0.000 \\
$\ln \mathrm{A} 3$ & -0.64702 & 0.076688 & -8.44 & 0.000 \\
cons & -1.3241 & 0.318882 & -4.15 & 0.000 \\
R2 & & 0.7541 & Number of samples & 210 \\
\hline
\end{tabular}




\section{Conclusions and Policy Recommendations}

\subsection{Conclusion}

In recent years, there has been a large gap in economic development across China, and the uncoordinated economic development has hindered the economy from advancing to a higher level. As an important driver of high-quality economic development, technological innovation has important theoretical and practical significance to study its impact on high-quality economic development, to achieve high-quality development, and to promote common prosperity. Using panel data of 30 provinces (cities, districts) in China from 2013 to 2019, this paper analyzes the high-quality economic development among various regions in China and the relationship between technological innovation and highquality economic development, and draws the following conclusions:

On the one hand, the economy as a whole shows a trend of steady growth and maintains a good economic situation, but the economic development gap between regions is becoming more and more obvious. Coastal areas with a high level of high-quality economic development can also maintain a large growth rate, and can achieve large economic growth and highquality economic development at the same time. The level of high-quality development in the inland frontier areas is low, and the economic growth rate is not large, so there is a bottleneck in economic development.

On the other hand, technological innovation can significantly promote high-quality economic development, and give full play to the important driving role of technological innovation in high-quality economic development. This shows that the national strategic science and technology construction has achieved good results, further improving the operation and overall efficiency of China's innovation system, and giving full play to the role of supporting and leading the high-quality economy.

\subsection{Policy Suggestions}

From the perspective of the level of high-quality economic development, to promote the process of high-quality economic development in China, we must pay attention to the coordinated development of regions. The wealth gap between regions will not only hinder China's high-quality economic development, but may also cause a series of social problems. Eliminate polarization, shorten the gap between the rich and the poor, let developed regions lead the economic development of relatively poor regions to a higher level, and promote high-quality economic development through common prosperity.

From the perspective of technological innovation, we must adhere to the strategy of "rejuvenating the country through science and education", always take technological innovation as the core, further improve the mechanism system for transforming technological innovation achievements into economic benefits, promote its wide application in various fields, and combine technology and economy. Development is closely linked to maximize the role of technological innovation in promoting high-quality development, continue to deepen the role of technological innovation, achieve digital transformation and structural upgrading in all walks of life, and cater to the current development trend. The government should formulate reasonable policies, formulate sound environmental regulations, encourage enterprises to innovate, master core technologies, accelerate the modernization process, promote the optimization of China's industrial structure, better play the leading role of technological innovation, and form innovation synergies in technological management system, and promote the realization of highquality economic development by effectively serving various fields.

\section{Acknowledgment}

This work is supported by Graduate Research and Innovation Fund Project of Anhui University of Finance and Economics, "Impact analysis of financial technology on highquality regional economic development and spillover effect"(No. ACYC2021368).

\section{References}

[1] Guo Ruiping, Li Dandan. Xi Jinping's inheritance and development of Deng Xiaoping's thought of common prosperity [J]. Journal of the Party School of the Yunnan Provincial Committee of the Communist Party of China, 2020, 21(03): 49-53.

[2] Luo Jing. Analysis on the connotation path of high-quality development in the frontier from the perspective of common prosperity [J]. Observation and Reflection, 2021(10):54-61.

[3] Zhang Libin. Promoting the realization of higher-quality employment under the new situation [J]. China Human Resources and Social Security, 2021(03):9-11.

[4] Zhang Xiaoming. Research on the operation mode and development strategy of Internet finance [D]. Shanxi University of Finance and Economics, 2015.

[5] Liang Chao. An Analysis of Deng Xiaoping's Thought of Common Prosperity in Contemporary China [J]. Journal of Hubei University of Economics (Humanities and Social Sciences Edition), 2017, 14(07): 5-7.

[6] Gao Haibo. Chinese Wisdom to Eliminate Poverty and Promote Common Prosperity: An Economic Philosophical Interpretation Based on the Anti-poverty Theory of Das Kapital [J/OL]. Journal of Dalian University of Technology (Social Science Edition): 1-8.

[7] Liu Libo, Zeng Yiman, Sun Yan, Pan Zhekang. Construction of a statistical monitoring and evaluation index system for high-quality regional economic development [J]. China Statistics, 2018(12):62-64

[8] Zhao Jianbo, Shi Dan, Deng Zhou. Research on the connotation of high-quality development [J]. Economics and Management Research, 2019, 40(11): 15-31.

[9] Cao Xiaochen. Research on the evaluation of high-quality economic development in Heilongjiang Province based on entropy weight method [J]. Commercial Economy, 2021 (03): $27-28+75$.

[10] Li Ruiji. The scientific connotation and realization of highquality economic development in the new era $[\mathrm{J}]$. Northern Economic and Trade, 2021(10):10-12.

[11] Miao Liran. Research on the impact of scientific and technological innovation in colleges and universities on highquality economic development [D]. Hebei University, 2020.

[12] Lu Mingxiang, Zhang Liyun. Research on the impact of technological progress and consumption structure upgrade on regional economic development: an empirical analysis of 
western region data from the perspective of efficiency [J]. Price Theory and Practice, 2020(10):139-142 +179.

[13] Ran Zheng, Zheng Jianghuai. Innovation ability and highquality development of regional economy-Analysis based on the perspective of technological differences [J]. Shanghai Economic Research, 2021(04): 84-99.

[14] Xu Menyou. Research on the construction of a modern and powerful country in the new era [M]. Shaanxi People's Publishing House: 2019.

[15] Su Weihua. Research on the theory and method of multi-index comprehensive evaluation [D]. Xiamen University, 2000.
[16] Wang Jianshi. Research on the impact of environmental regulation on the upgrading of regional industrial structure [D]. Shandong Normal University, 2020.

[17] Wu Yunliang, Qian Jiajing, Zhang Tinghai. Environmental regulation, green technology innovation and high-quality economic development in the Yangtze River Delta [J]. East China Economic Management, 2021, 35(12): 30-42.

[18] Zhang Hui, Yan Qiangming, Huang Hao. Problems, impacts and countermeasures of China's structural transformation from an international perspective [J]. China Industrial Economy, 2019(06): 41-59.

[19] Tao Changqi, Xu Ye, Wan Jianxiang. Econometrics [M]. Nanjing University Press, 2021. 